Jurnal Media Komunikasi Pendidikan Pancasila dan Kewarganegaraan

Volume 2, Nomor 1 April 2020

\title{
PERSPEKTIF KEJAHATAN SINYAL DALAM KASUS EKSPLORASI GEOTHERMAL DI GUNUNG SLAMET, KABUPATEN BANYUMAS
}

\author{
Arief Awaludin \\ Faculty of Law, Universitas Wijayakusuma, Purwokerto - Indonesia \\ Rusito \\ Faculty of Law, Universitas Wijayakusuma, Purwokerto - Indonesia
}

\begin{abstract}
Geothermal exploration in the Mount Slamet area of Banyumas Regency is an economic activity that results in environmental damage. Various complaints and protests were revealed. Communities experience social, physical and economic losses due to these events. The absence of a loss approach, especially social loss in understanding the incident resulted in the absence of criminal sanctions for the perpetrators. Though these actions are included in the category of environmental crime. The research method comes from secondary data in the form of mass media coverage and qualitative analysis used in this study. Based on the facts and findings and in-depth analysis, it was concluded that there were signs of crime due to geothermal exploration in Banyumas. A signal crime approach is needed in assessing these events to prove the existence of environmental crimes. This awareness and social reaction to environmental crimes can be realized because of the movement of civil society that cares.
\end{abstract}

Keywords: signal crimes, geothermal exploration, banyumas regency

\begin{abstract}
Abstrak
Eksplorasi panas bumi di kawasan Gunung Slamet Kabupaten Banyumas merupakan kegiatan ekonomi yang mengakibatkan kerusakan lingkungan. Berbagai keluhan dan protes pun terungkap. Masyarakat mengalami kerugian sosial, fisik, dan ekonomi akibat peristiwa ini. Tidak adanya pendekatan kerugian, terutama kerugian sosial dalam memahami kejadian tersebut mengakibatkan tidak adanya sanksi pidana bagi para pelaku. Padahal tindakan ini termasuk dalam kategori kejahatan lingkungan. Metode penelitian berasal dari data sekunder berupa liputan media massa dan analisis kualitatif yang digunakan dalam penelitian ini. Berdasarkan fakta dan temuan serta analisis mendalam, disimpulkan bahwa ada tanda-tanda kejahatan akibat eksplorasi panas bumi di Banyumas. Pendekatan sinyal kejahatan diperlukan dalam menilai peristiwaperistiwa ini untuk membuktikan keberadaan kejahatan lingkungan. Kesadaran dan reaksi sosial ini terhadap kejahatan lingkungan dapat diwujudkan karena gerakan masyarakat sipil yang peduli.
\end{abstract}

Kata Kunci: sinyal kejahatan, eksplorasi panas bumi, Kabupaten banyumas 


\section{Pendahuluan}

Gunung Slamet adalah gunung tertinggi di Jawa Tengah; dikelilingi oleh lima kabupaten di Indonesia (yaitu Banyumas, Purbalingga, Pemalang, Tegal dan Brebes). Kemiringan selatan Gunung Slamet (yang termasuk wilayah administrasi Kabupaten Banyumas) adalah ekosistem yang dilindungi dan terpelihara dengan baik dengan pohon-pohon hijau dan keanekaragaman hewan yang dilindungi. Gunung Slamet adalah sumber air utama bagi Kabupaten Banyumas karena memiliki sungai besar seperti Banjaran, Gumawang dan Logawa. Sungai-sungai ini adalah air terbesar yang terletak di Banyumas. Ini adalah satu-satunya gunung dengan keanekaragaman hayati besar di Jawa Tengah bagian barat $^{1}$. Namun, pembangunan Pembangkit Listrik Tenaga Panas Bumi di lereng selatan menimbulkan ancaman besar bagi ekosistemnya. ${ }^{2}$ Konstruksi ini dapat mengakibatkan pergeseran ekosistem; beberapa organisme hidup yang mungkin terpengaruh termasuk burung dan primata seperti monyet, kera dan lemur. Kejahatan Margasatwa dan Hutan (WLFC) adalah masalah serius dan terus berkembang. Kegiatan kriminal WLFC tidak hanya menimbulkan ancaman serius bagi keanekaragaman hayati dan pelestarian satwa liar, tetapi juga

1 http://revolusitotal.org/gunung-slametyang-tak-lagi-selamat/ di akses pada 24 April 2020

${ }^{2}$ https://www.vebma.com/opini/pembanguna n-proyek-pembangkit-listrik-tenagapanas-bumi-di-gunungslamet/16706\#ixzz5LPaNKd2w di akses pada 24 April 2020 mengakibatkan hilangnya potensi pendapatan yang besar bagi pemerintah yang jika tidak akan dihasilkan melalui perdagangan legal, misalnya dalam penjualan sumber daya seperti kayu. Konsekuensi negatif dari hilangnya pendapatan yang signifikan ini adalah ketidakmampuan untuk menginvestasikan kembali dan mendukung peluang pembangunan. Peran publik dan masyarakat sipil sangat penting dalam memerangi WLFC.

Kehadiran PT Sejahtera Alam Energy (SAE) yang akan membangun Pembangkit Listrik Tenaga Panas Bumi di Baturraden telah menciptakan reaksi sosial di Jawa Tengah. Ini tercermin dalam ketidaksetujuan kegiatan yang dapat mengakibatkan dampak lingkungan yang merugikan dan reaksi sosial dari penduduk kabupaten. Tanda ini mungkin merupakan indikasi kejahatan lingkungan yang dirasakan sebagai hasil dari perintah kegiatan eksplorasi panas bumi di Gunung Slamet, Baturaden.

Organisasi masyarakat sipil (LSM) dapat memberikan pertolongan segera dan perubahan transformatif jangka panjang dengan membela kepentingan kolektif dan meningkatkan akuntabilitas; menyediakan mekanisme solidaritas dan mendorong partisipasi; mempengaruhi pengambilan keputusan; terlibat langsung dalam pemberian layanan; dan prasangka

\footnotetext{
${ }^{3}$ Global_Programme_for_Combating_Wildli fe_and_Forest_Crime di akses pada 25 April 2020
} 
yang menantang. ${ }^{4}$ Masyarakat sipil diperlukan dalam menjaga kelestarian lingkungan. Meningkatnya masyarakat sipil akan meningkatkan daya saing bangsa. ${ }^{5}$

$$
\text { Istilah "sinyal kejahatan" }
$$

pertama kali dinyatakan oleh Martin

Innes pada tahun 2004 perspektif Martin memberikan cara inovatif untuk mendefinisikan dan menerjemahkan kejahatan dan gangguan secara bermakna kepada masyarakat. Perspektif ini juga membantu menggambarkan bagaimana karakter sosial ruang fisik dapat dibangun secara simbolis. Sinyal kejahatan dapat didefinisikan sebagai peristiwa yang memiliki risiko kriminogenisitas tinggi. Sementara penyimpangan gangguan memiliki dua bentuk utama. Itu tergantung pada ekspresi denotatif, baik fisik maupun sosial, dan berkonotasi dengan adanya risiko yang tidak diinginkan. ${ }^{6}$ Dari perspektif ini, bukan keseriusan suatu peristiwa (namun diukur), tetapi nilai sinyal dari suatu peristiwa yang memiliki pengaruh terbesar. Ini akan dipengaruhi oleh berbagai faktor seperti persepsi keseriusan dan dampak pada individu atau lingkungan, frekuensi, waktu dan

4 https://gsdrc.org/topic-guides/socialexclusion/lessons-and-tools/the-role-ofcivil-society-and-social-movements/ di akses pada 25 April 2020

5 Dwi Sulisworo, (2013) Peningkatan Civil Society untuk Kemajuan Ilmu Pengetahuan Teknologi dan Ketahanan Bangsa, Yogyakarta: Cetta Media, 2013

6 I. Martin, (2004), Signal Crimes And Signal Disorders: Notes On Deviance As Communicative Action British Journal Of Sociology Vol.55 Issue 3 https://doi.org/10.1111/j.14684446.2004.00023.x lokasi peristiwa, harapan perilaku, dan liputan media. ${ }^{7}$

Sinyal kejahatan dapat didefinisikan sebagai dan insiden yang secara tidak proporsional memengaruhi individu untuk merasa bahwa mereka berisiko. ${ }^{8}$ Penelitian yang dilakukan oleh Roach, Alexander dan Pease menegaskan pentingnya "sinyal kejahatan" dalam pembuatan kebijakan dan pencegahan kejahatan. ${ }^{9} \quad$ Pikiran tentang sinyal dan pensinyalan membuka cara baru untuk melihat kejahatan, gangguan, dan kontrol sosial. Sinyal kejahatan telah menjadi unit analisis utama untuk mengukur dampak kejahatan dalam bentuk agregat. ${ }^{10}$

Perspektif Kejahatan Sinyal, seperti yang pada prinsipnya dikembangkan oleh Innes (2004), mengkritik model-model kriminologis sebelumnya yang menghadirkan hubungan linier antara gangguan lokal, ketakutan terhadap kejahatan dan tingkat kejahatan aktual. Innes mengembangkan pendekatan untuk membongkar

7 Caless, Bryn, (2015) Policing, 9, 3, https://doi.org/10.1093/police/pau059 di akses pada 28 April 2020

8 I. Martin, (2004), Signal Crimes And Signal Disorders: Notes On Deviance As Communicative Action British Journal Of Sociology Vol.55 Issue 3 https://doi.org/10.1111/j.14684446.2004.00023.x

9 Millie, Andrew. 'Reassurance Policing and Signal Crimes', in G. Bruinsma snd D. Weisburd (eds.) Encyclopedia of Criminology and Criminal Justice, (Springer : New York, 2014)

10 I. Martin, N. Fielding, (2002) From Community to Communicative Policing: Signal crimes and The Problem of Public Reassurance. Social, Res Online 7, 2 Available at: www.socresonline.org.uk 
bagaimana orang menafsirkan kejahatan dan gangguan, dengan fokus pada bagaimana kejahatan atau insiden gangguan tertentu 'diekspresikan' (bagaimana seseorang menggambarkan kejahatan atau gangguan), efeknya (bagaimana dampaknya pada mereka dalam hal perilaku, pemikiran, atau perasaan), dan akhirnya isinya (bagaimana insiden menginformasikan perasaan risiko atau ancaman mereka). ${ }^{11}$

Dengan demikian, sinyal kejahatan adalah insiden yang, karena bagaimana hal itu ditafsirkan, berfungsi sebagai sinyal peringatan kepada orang-orang tentang distribusi risiko di seluruh ruang sosial. Prinsip mendasar dari konsep kejahatan sinyal adalah bahwa orang menafsirkan dan mendefinisikan insiden kriminal tertentu sebagai indikator tentang berbagai bahaya yang ada dalam kehidupan sosial kontemporer dan yang mungkin berpotensi menyerang mereka. ${ }^{12}$

$$
\text { Kejahatan lingkungan }
$$

umumnya didefinisikan sebagai kejahatan yang dilakukan terhadap lingkungan. Sebagian besar lembaga penegak hukum memecah kejahatan lingkungan menjadi dua kategori: polusi dan ancaman terhadap spesies yang terancam punah. Tumbuhnya kesadaran akan isu-isu lingkungan menyebabkan tindakan keras terhadap kejahatan lingkungan di banyak negara selama abad kedua puluh, dan lembaga-lembaga penegak hukum utama menganggap

\footnotetext{
${ }^{11}$ http://www.sipr.ac.uk/Plugin/Publications/ assets/files/I-NSI 2012.pdf HAL 2 di akses pada 26 April 2020

12 Martin Innes, (2004), Crime as a Signal, Crime as a Memory, Journal for Crime, Conflict and the Media (2) 15-22
}

kejahatan lingkungan sangat serius. Tidak hanya merusak lingkungan, tetapi sering berdampak pada ekonomi dan kualitas hidup secara umum juga. Ketika kejahatan lingkungan dilakukan, pada umumnya bukan karena keinginan untuk menghancurkan lingkungan, meskipun memiliki efek akhir yang menyebabkan kerusakan lingkungan. $^{13}$

Penentuan "kejahatan lingkungan" diterapkan pada perilaku daripada ketentuan hukum yang harus dilindungi baik secara ekologis maupun fisik ${ }^{14}$. Kejahatan lingkungan adalah tindakan ilegal yang secara langsung membahayakan lingkungan ${ }^{15}$. Kejahatan lingkungan memiliki konsekuensi yang merugikan pada keamanan suatu negara. Untuk individu dan masyarakat, ini mungkin memiliki dampak negatif pada kesehatan masyarakat, mata pencaharian, nilai properti, spesies non-manusia, dan generasi masa $\operatorname{depan}^{16}$.

Kejahatan lingkungan yang luas dapat didefinisikan sebagai tindakan ilegal yang secara langsung berbahaya bagi lingkungan. Tindakan ilegal ini termasuk

13 https://www.wisegeek.com/what-is-anenvironmental-crime.htm di akses pada 26 April 2020

14 Clifford, Mary, T. D. (1998) Edwards.. "Defining 'Environmental Crime.' "In Environmental Crime: Enforcement, Policy, and Social Responsibility (edited by Mary Clifford. Gaithersburg, Md.: Aspen

15 W. R. Korir, (2013) Environmental Crime Management In Kenya, (Thesis, University of Nairobi, 2013)

16 M. O‘Hear, (2004). Journal of Criminal Law and Criminology, Vol.1, Issues 95, P. 133 
perdagangan ilegal satwa liar, penyelundupan bahan perusak ozon (ODS), perdagangan ilegal limbah berbahaya, ilegal, penangkapan ikan yang tidak diatur, dan tidak dilaporkan, dan pembalakan liar serta perdagangan terkait produk kayu curian $^{17}$. Kejahatan lingkungan adalah kejahatan terbesar keempat setelah perdagangan narkoba, pemalsuan dan perdagangan manusia. Kejahatan lingkungan bukanlah ancaman baru; jenis kejahatan ini menjadi lebih serius dan terorganisir di berbagai belahan dunia ${ }^{18}$. Kejahatan lingkungan di Indonesia diatur oleh UU No. 32/2009 tentang Perlindungan dan Pengelolaan Lingkungan ${ }^{19}$.

Penelitian ini bertujuan untuk mengidentifikasi dan menyelidiki fenomena reaksi sosial terhadap kejahatan. Ini mulai dari sinyal kejahatan lingkungan hingga munculnya tuntutan penegakan hukum. Penelitian ini dilakukan dengan memeriksa liputan media yang berkaitan dengan sinyal kejahatan lingkungan dari kegiatan eksplorasi panas bumi di Baturaden yang telah menimbulkan protes dari waktu ke waktu. Media massa memiliki dampak yang signifikan

17 M. Rice, (2008) Environmental Crime: A threat to Our Future, Environmental Investigation Agency (EIA), Editor, London

18 A.R. Andriani, (2017) Serious and Growing. Environmental Crime Tackling the Greatest Threats to Our Planet, Our Planet, United Nation Environment Programme

19 http://jdih.menlh.go.id/pdf/ind/INDPUU-1-2009-

UU\%20No.\%2032\%20Th\%202009

Com-bi ne.pdf di akses pada 25 April 2020 terhadap munculnya reaksi sosial karena media massa membingkai gambar-gambar realitas dengan cara yang dapat diprediksi dan berpola ${ }^{20}$. Saya ingin menyarankan agar caracara media melaporkan pelanggaran tertentu, berkontribusi pada fungsinya sebagai 'sinyal kejahatan'.

\section{Metodologi Penelitian}

Pendekatan

kualitatif digunakan dalam penelitian ini. Pertama, konteks kejahatan dimensi kejahatan lingkungan didirikan dalam penelitian ini. Kedua, liputan media massa (antara periode Januari 2017 hingga Juni 2018) tentang reaksi masyarakat terhadap eksplorasi panas bumi oleh PT SAE di Baturaden Banyumas dibahas. Ketiga, tingkat ancaman kejahatan yang dilaporkan berfungsi sebagai dasar untuk analisis konsep sinyal kejahatan. Penelitian ini berupaya menyoroti bagaimana media menyajikan berita tentang sinyal kejahatan lingkungan dan menggambarkan munculnya sinyal kejahatan lingkungan.

\section{Hasil Dan Pembahasan}

Gunung slamet adalah gunung berapi aktif tertinggi di Jawa Tengah dengan hutan tropis alami di pulau Jawa. Berbagai flora dan fauna hidup di Gunung Slamet; organisme ini berkisar dari macan tutul, elang Jawa, anggrek gunung hingga spesies katak yang belum disebutkan namanya di Gunung Slamet. Semua organisme ini hidup di Gunung Slamet karena hutannya lembab dan kondisi tanah basah karena

\footnotetext{
20 Mc Quail, D. (1994) Mass communication: An Introduction. (3rd edition). Thousand Oaks, CA: Sage.
} 
pengambilan air dari sungai-sungai besar di Gunung Slamet. Kondisi ini menjadikan Slamet sumber air yang cocok untuk organisme hidup di sekitar lingkungan. Masyarakat sekitar sangat bergantung pada Gunung Slamet untuk berbagai kegiatan kehidupan seperti pertanian, perikanan, kehutanan dan pariwisata. Namun, kondisi di Gunung Slamet berubah secara instan setelah kedatangan proyek pengembangan energi panas bumi (PLTP). PLTP adalah pembangkit listrik yang memanfaatkan energi panas bumi sebagai sumber energinya. ${ }^{21}$

Berdasarkan

Keputusan

Gubernur Jawa Tengah, No. 541/27/2011 tanggal 11 April 2011, PT Sejahtera Alam Energy (SAE) memperoleh izin untuk mendirikan bisnis pertambangan panas bumi di wilayah Baturraden. Lokasi proyek mencakup 24.660 hektar (ha) dan mencakup kabupaten-kabupaten berikut: Banyumas, Purbalingga, Tegal, Brebes, dan Pemalang. Arty memperoleh izin pinjaman untuk kawasan hutan lindung dari Kementerian Kehutanan untuk memulai pengembangan panas bumi di lereng Gunung Slamet pada 13 Agustus 2012. Luas izin pemanfaatan adalah 44 hektar sebagai titik awal untuk eksplorasi. ${ }^{22}$

Kegiatan proyek panas bumi mengancam keseimbangan ekosistem di Gunung Slamet.

\footnotetext{
${ }^{21}$ https://www.vebma.com/opini/pembangun an-proyek-pembangkit-listrik-tenagapanas-bumi-di-gunung-slamet/ 16706\#ixzz5MXbgDKKv di akses pada 30 April 2020

${ }^{22}$ https://tekno.kompas.com/read/2012/10/12 /10295762/ investor.pltp.baturraden .kantongi.izin. kemenhut di akses pada 30 April 2020
}

Deforestasi yang terjadi di kawasan hutan gunung membongkar hutan besar dan mengakibatkan kerusakan dan polusi beberapa saluran sungai, termasuk sungai Logawa. ${ }^{23}$ Sungaisungai yang mengalir melalui 13 desa di Banyumas mengalami kekeruhan akibat pencemaran lumpur. ${ }^{24}$ Kegiatan eksplorasi yang disertai dengan penggundulan hutan juga mengakibatkan terjadinya banjir bandang dan tanah longsor, khususnya di daerah pegunungan. Setelah fase eksplorasi selesai, fase eksploitasi dimulai. Fase ini mencakup dua kegiatan utama: pengeboran dan produksi listrik. Dampak dari kegiatan-kegiatan ini menghasilkan terjadinya gempa bumi kecil 3,4 hingga 5 pada skala Richter. Gempa bumi mengakibatkan retaknya bangunan dan kontaminasi lingkungan dengan limbah pembangkit listrik tenaga panas bumi. Zat beracun dalam limbah termasuk, Arsenik, Antimon dan Baron $^{25}$. Pada 15 Oktober 2017, banjir bandang terjadi karena hujan deras di bagian atas sungai dan lereng Gunung Slamet. Korban banjir bandang adalah mereka yang tinggal di sekitar sungai Banjaran, Pelus, Logawa dan Prukut ${ }^{26}$. Saat ini, ratusan hektar hutan lindung di

23 http://wartahijau.com/read/pembangunanpltp-meningkatkan-risiko-bencana. di akses pada 24 April 2020

${ }^{24} \mathrm{http}: / /$ independen.id/read/peristiwa/256/pe ncemaran-lingkungan-pltp-lerengslamet/ di akses pada 24 April 2020

$25 \mathrm{http}: / /$ kopibackpacker.blogspot.com/2017/07/damp ak-mengerikan-dari-pltp-gunung.html

26 https://banyumasnews.com/98224/banjirbandang-landa-banyumas-dampakproyek-pltp-baturraden/ di akses pada 28 April 2020 
kawasan Gunung Slamet telah dieksplorasi sebagai hasil dari proyek Pembangkit Listrik Tenaga Panas Bumi (PLTP) Baturaden. Ini berpotensi menyebabkan kerusakan lingkungan di kawasan itu, termasuk kawasan wisata yang banyak dikunjungi wisatawan. Saat ini, PT SAE telah memulai tahap eksplorasi. Total area hutan lindung yang telah dibuka untuk eksplorasi adalah 675,7 hektar. Kegiatan penebangan juga telah dimulai di daerah Rawa Taman Dringo dan Bukit Rata Amba. Ini menghasilkan peningkatan deforestasi dan berkurangnya penyerapan air. Dimulainya fase eksplorasi telah menghasilkan ketidakseimbangan ekosistem. Hewan-hewan dari Gunung Slamet sering muncul di desa-desa atau di tepi hutan dan merusak lahan pertanian rakyat. Pembangunan PLTP Baturaden juga berdampak buruk pada masyarakat yang membentuk lima kabupaten di Jawa Tengah, (termasuk Kabupaten Banyumas, Kabupaten Brebes, Kabupaten Tegal, Kabupaten Pemalang dan Kabupaten Purbalingga). ${ }^{27}$

Masyarakat sebagai korban langsung dari proyek pembangkit listrik tenaga panas bumi (PLTP) telah bereaksi terhadap dampak merugikan dari dimulainya rencana pembangunan, ${ }^{28} \quad$ khususnya penduduk Desa Melung, Kabupaten

27

http://www.suarakarya.id/detail/50659/ Proyek-PLTP-Baturaden-AncamLingkungan-Hidup-Seputar-GunungSlamet di akses pada 24 April 2020

28 https://www.melung.desa.id/adakahdampak-lingkungan-di-wilayah-kami/ di akses pada 28 April 2020
Baturaden, dan Kabupaten Bayumas. Eskalasi reaksi publik juga meningkat. Selama peringatan Hari Bumi, ratusan siswa mengadakan demonstrasi di alun-alun Purwokerto menuntut pembatalan proyek-proyek panas bumi. Protes ini didasarkan pada tuduhan bahwa PT Sejahtera Alam Energy (SAE) tidak memiliki lisensi Analisis Mengenai Dampak Lingkungan (AMDAL). Para siswa juga menunjukkan 31 foto kerusakan lingkungan yang disebabkan oleh kegiatan eksplorasi. ${ }^{29}$ Petisi ini diterbitkan secara online, untuk para siswa meminta dukungan komunitas mereka dan menuntut agar Presiden menghentikan proyek tersebut. ${ }^{30}$

Aliansi Petani Indonesia di 7 Kabupaten di sekitar Gunung Slamet juga memprotes pelaksanaan kegiatan eksplorasi. ${ }^{31}$ Puncak demonstrasi berlangsung 18 Juli 2017. Ratusan orang dari berbagai elemen masyarakat, yang tergabung dalam Aliansi Slamet Selamat menjalani sidang paripurna DPRD Banyumas, Jawa Tengah. ${ }^{32}$

29 https://www.mapalaptm.com/berita1599-peringati-hari-bumi-ratusanpelajar--mahasiswa-menolak-proyekpemerintah-pltp-di-gunung-slamet.html 30 di akses pada 27 April 2020

https://purwokertokita.com/lingkungan/ suara-suara-penolakan-pltp-di-gunungslamet.php https://www.change.org/p/pak-jokowicabut- izin-pltp-baturaden di akses pada 26 April 2020

https://www.pewartanusantara.com/alian si-petani-indonesia-proyek-pltp-ancampetani-lereng-gunung-slamet/ Di Akses 32 Pada 30 April 2020

https://regional.kompas.com/read/2017 /07/18/15165611/tolak-pembangkitlistrik-panas-bumi-massa-duduki- 
Masyarakat menuntut agar Bupati Banyumas mencabut izin eksplorasi panas bumi PT Sejahtera Alam Energy (SAE). Masyarakat menganggap pembangunan PLTP Baturaden sebagai kesalahan fatal yang dilakukan oleh pemerintah. ${ }^{33}$ Demonstrasi kembali terjadi pada 9 Oktober 2017 oleh masyarakat dari 3 kecamatan, yaitu Kecamatan Sumbang, Kecamatan Karanglewas dan Kabupaten Cilongok. Mereka menuntut agar Bupati mencabut izin eksplorasi PT SAE karena menyebabkan kerusakan pada lingkungan dan masyarakat. ${ }^{34}$ Demonstrasi berakhir dengan kekerasan oleh polisi; 15 pemrotes ditangkap dan dipukuli oleh polisi. Beberapa petugas polisi juga melanggar 28 orang dan merusak 2 ponsel, 2 sepeda motor, mobil komando dan tenda. ${ }^{35}$ Banyak orang menuntut penyelesaian kekerasan oleh petugas polisi terhadap para demonstran. Beberapa jurnalis yang meliput demonstrasi tidak melarikan diri sebagai korban. Oleh karena itu organisasi jurnalis Indonesia (PWI) dan Aliansi Jurnalis Indonesia (AJI) juga mengambil sikap atas insiden tersebut. $^{36} 37$

gedung-dprd-banyumas. di akses pada 24 April 2020

${ }^{33} \mathrm{https}: / / w w w \cdot h e t a n e w s . c o m / a r t i c l e / 100966 /$ ratusan-demonstran-tuntut-bupati-

banyumas-cabut-izin-pltp-baturraden di akses pada 28 April 2020

${ }^{34} \mathrm{https}$ ://www.gatra.com/rubrik/nasional/pe merintahan-daerah/289305-ratusanwarga-lereng-selatan-gunung-slametdemo-tuntut-ijin-pltp-dicabut di akses pada 28 April 2020

35 http://buruh.co/polisi-lakukan-kekerasanpada-aksi-selamatkan-gunung-slamet/ di akses pada 25 April 2020

${ }^{36} \mathrm{https}: / / \mathrm{www}$. republika.co.id/berita/nasional /hukum/17/10/10/oxlkz2318-pwi-proses-
Berdasarkan proses munculnya reaksi sosial, sinyal perspektif kejahatan diungkapkan oleh Martin Innes. Terlihat bahwa berita media memberikan penguatan pada berbagai sinyal kejahatan yang terjadi ketika kegiatan eksplorasi panas bumi dilakukan di Gunung Slamet, Baturaden. Sinyal kejahatan seperti yang dilaporkan oleh media berita mencakup tiga hal: ekspresi, konten, dan efek. ${ }^{38}$

\section{Penutup}

Kegiatan eksplorasi panas bumi yang dilakukan oleh PT Sejahtera Alam Energi (SAE) di Baturraden mendapat reaksi negatif dari masyarakat yang tinggal di Gunung Slamet. Izin eksplorasi panas bumi yang dimiliki oleh PT SAE tidak mematuhi hukum pengelolaan dan perlindungan lingkungan Indonesia. Berbagai dampak negatif yang disebabkan oleh kegiatan eksplorasi merusak lingkungan alam Gunung Slamet, mengancam keamanan masyarakat dan merugikan masyarakat. Hal ini mengakibatkan munculnya kepanikan moral yang dilaporkan oleh media selama periode 2017 hingga pertengahan 2018. Sinyal kejahatan lingkungan itu nyata. Perlu perhatian, kepedulian, dan perlindungan bagi masyarakat dan

\footnotetext{
hukum-pelaku-kekerasan-jurnalis-

banyumas di akses pada 25 April 2020

37 https://www.kabargayo.com/aji-kotapurwokerto-kecam-kekerasanpembubaran-paksa-demo-tolak-pltpbaturraden di akses pada 24 April 2020

38 The Signal Crime Perspective, (2008), Sixty Second Briefing, Universitie's Policy Science Institute, Cardiff University.
} 
Jurnal Media Komunikasi Pendidikan Pancasila dan Kewarganegaraan Volume 2, Nomor 1 April 2020

alam di sekitar Gunung Slamet, Baturaden. Berbagai undang-undang dan peraturan tentang eksplorasi lingkungan dan panas bumi perlu dipertimbangkan.

\section{Daftar Pustaka}

A.R. Andriani, (2017) Serious and Growing. Environmental Crime Tackling the Greatest Threats to Our Planet, Our Planet, United Nation Environment Programme

Caless, Bryn, (2015) Policing, 9, 3, https://doi.org/10.1093/police/p au059 I. Martin, BJS 553

Clifford, Mary, T. D. (1998) Edwards.. "Defining 'Environmental Crime.' "In Environmental Crime: Enforcement, Policy, and Social Responsibility (edited by Mary Clifford. Gaithersburg, Md.: Aspen

Dwi Sulisworo, (2013) Peningkatan Civil Society untuk Kemajuan Ilmu Pengetahuan Teknologi dan Ketahanan Bangsa, Yogyakarta: Cetta Media, 2013

Global Programme for Combating $\bar{W}$ ildlife_and_Forest_Crime

http://buruh.co/polisi-lakukankekerasan-pada-aksiselamatkan-gunung-slamet/

http://independen.id/read/peristiwa/2 56/pencemaran-lingkunganpltp-lereng-slamet/

http://jdih.menlh.go.id/pdf/ind/INDPUU-1-2009-

UU\%20No.\%2032\%20Th\%20

http://kopi2009_Combine.pdf

backpacker.blogspot.com/2017 /07/dampak-mengerikan-daripltp-gunung.html http://revolusitotal.org/gunungslamet-yang-tak-lagi-selamat/

http://wartahijau.com/read/pembangu nan-pltp-meningkatkan-risikobencana.

http://www.sipr.ac.uk/Plugin/Publica tions/assets/files/INSI_2012.pdf HAL 2

http://www.suarakarya.id/detail/5065 9/Proyek-PLTP-BaturadenAncam-Lingkungan-HidupSeputar-Gunung-Slamet

https://banyumasnews.com/98224/ba njir-bandang-landa-banyumasdampak-proyek-pltpbaturraden/

https://gsdrc.org/topic-guides/socialexclusion/lessons-andtools/the-role-of-civil-societyand-social-movements/

https://purwokertokita.com/lingkung an/suara-suara-penolakan-pltpdi-gunung-slamet.php https://www.change.org/p/pakjokowi-cabut- izin-pltpbaturaden

https://regional.kompas.com/read/20 17/07/18/15165611/tolakpembangkit-listrik-panasbumi-massa-duduki-gedungdprd-banyumas.

https://tekno.kompas.com/read/2012/ 10/12/10295762/ investor.pltp.baturraden .kantongi.izin.kemenhut

https://www.gatra.com/rubrik/nasion al/pemerintahandaerah/289305-ratusan-wargalereng-selatan-gunung-slametdemo-tuntut-ijin-pltp-dicabut

https://www.hetanews.com/article/10 0966/ratusan-demonstrantuntut-bupati-banyumas-cabutizin-pltp-baturraden

https://www.kabargayo.com/aji-kotapurwokerto-kecam-kekerasan- 
Jurnal Media Komunikasi Pendidikan Pancasila dan Kewarganegaraan

Volume 2, Nomor 1 April 2020

pembubaran-paksa-demo-

tolak-pltp-baturraden

https://www.mapalaptm.com/berita-

1599-peringati-hari-bumiratusan-pelajar--mahasiswamenolak-proyek-pemerintahpltp-di-gunung-slamet.html https://www.melung.desa.id/adakahdampak-lingkungan-diwilayah-kami/

https://www.pewartanusantara.com/a liansi-petani-indonesia-proyekpltp-ancam-petani-lerenggunung-slamet/

https://www.republika.co.id/berita/na sional/hukum/17/10/10/oxlkz2 318-pwi-proses-hukum-pelakukekerasan-jurnalis-banyumas

https://www.vebma.com/opini/pemb angunan-proyek-pembangkitlistrik-tenaga-panas-bumi-digunungslamet/16706\#ixzz5LPaNKd2 $\mathrm{W}$

https://www.vebma.com/opini/pemb angunan-proyek-pembangkitlistrik-tenaga-panas-bumi-digunung-slamet/ 16706\#ixzz5MXbgDKKv

https://www.wisegeek.com/what-isan-environmental-crime.htm

I. Martin, (2004) Signal Crimes And Signal Disorders: Notes On Deviance As Communicative Action British Journal Of Sociology Vol.55 Issue 3 https://doi.org/10.1111/j.14684446.2004.00023.x

I. Martin, N. Fielding, (2002) From Community to Communicative Policing: Signal crimes and The Problem of Public Reassurance. Social, Res Online 7, 2 Available at: www.socresonline.org.uk
M. O‘Hear, (2004). Journal of Criminal Law and Criminology, Vol.1, Issues 95, P. 133

M. Rice, (2008) Environmental Crime: A threat to Our Future, Environmental Investigation Agency (EIA), Editor, London

Martin Innes, (2004), Crime as a Signal, Crime as a Memory, Journal for Crime, Conflict and the Media (2) 15-22

McQuail, D. (1994) Mass communication: An Introduction. (3rd edition). Thousand Oaks, CA: Sage.

Millie, Andrew. 'Reassurance Policing and Signal Crimes', in G. Bruinsma snd D. Weisburd (eds.) Encyclopedia of Criminology and Criminal Justice, (Springer : New York, 2014)

The Signal Crime Perspective, (2008), Sixty Second Briefing, Universitie's Policy Science Institute, Cardiff University.

W. R. Korir, (2013) Environmental Crime Management In Kenya, (Thesis, University of Nairobi, 2013) 